\section{Inheritance of Phosphoglucomutase and Menadione Reductase Isozymes in Guayule (Parthenium argentatum)}

\author{
A. Hashemi ${ }^{1}$ and A. Estilai ${ }^{2}$ \\ Department of Botany and Plant Sciences, University of California, \\ Riverside, CA 92521
}

Additional index words. starch gel electrophoresis, natural rubber, apomixis, breeding

Abstract. Leaf extracts of diploid guayule were analyzed for phosphoglucomutase (PGM, EC 2.7.5.1) and menadione reductase (MNR, EC 1.6.99.2) isozymes by starch gel electrophoresis. Banding patterns of hybrids indicated that PGM is monomeric and MNR tetrameric in structure. Two codominant alleles were identified at each of two Pgm loci, designated as Pgm-2 and Pgm-3. Two codominant alleles were observed at Mnr-2; MNR-1 was monomorphic in the Parthenium argentatum genotypes analyzed.

Guayule, a desert shrub from Mexico and southwestern Texas, is the only species of the genus Parthenium that produces appreciable amounts of rubber. Interest in reducing national dependence on foreign sources of rubber has greatly stimulated guayule breeding efforts.

Guayule breeding behavior is complex. Depending on the ploidy level, guayule reproduces sexually or apomictically. Diploids are sexual and self-incompatible. Polyploids are facultative apomicts, producing predominantly maternal-type progeny (Esau, 1944; Gerstel and Mishanec, 1950). Simple biochemical markers are needed to save time and effort in identifying crossed and apomictic progeny at the early seedling stage. These markers can be used to determine the degree of apomixis of various genotypes, to finger-

Received for publication 3 June 1991. Accepted for publication 27 Sept. 1991. Research was supported in part by U.S. Dept. of Agriculture Grant 89-38200-4375 and U.S. Dept. of Agriculture/ CSRS Cooperative Agreement no. 89-COOP-14949. The cost of publishing this paper was defrayed in part by the payment of page charges. Under postal regulations, this paper therefore must be hereby marked advertisement solely to indicate this fact:

${ }^{1}$ Postgraduate Geneticist.

${ }^{2}$ Associate Research Agronomist. progeny between enzyme variants were generated (Table 1) following the procedures described by Hashemi et al. (1986). Crosses were also made between $P$. argentatum and $P$. tomentosum DC to verify the tetrameric structure-of menadione reductase. Leaf extracts were obtained from greenhouse-grown plants. The extraction buffer consisted of 30 mg DL-dithiothreitol (DTT), 3 g polyvinylpyrrolidone (PVP-40), four drops of 2-mercaptoethanol, and $20 \mathrm{ml} 0.1 \mathrm{M}$ TrisHCl $(\mathrm{pH}$ 8.0). Phosphoglucomutase was resolved on a continuous buffer system. The gel consisted of $9.6 \%$ starch and 0.009 M L-histidine, titrated to $\mathrm{pH} 6.0$ with citric acid. The electrode buffer was $0.065 \mathrm{M}$ L-histidine, titrated to $\mathrm{pH} 6.0$ with citric acid (Ellstrand, 1984). Menadione reductase (MNR, EC 1.6.99.2) was resolved on a discontinuous buffer system. The gel consisted of $10.9 \%$ starch, $0.051 \mathrm{M}$ Tris, $0.0076 \mathrm{M}$ citric acid, $0.058 \mathrm{~mm} \mathrm{LiOH}$, and $0.0038 \mathrm{M}$ boric acid. The electrode buffer was $0.91 \mathrm{M}$ boric acid and $0.029 \mathrm{M} \mathrm{LiOH}$ (Heywood, 1980). In the continuous system, gels were run at $150 \mathrm{~V}$ and $25 \mathrm{~mA}$ for $6 \mathrm{~h}$ and then stained for PGM (Garvin, 1987). In the discontinuous system, gels were run at $200 \mathrm{~V}$ and $75 \mathrm{~mA}$ for 5 to $6 \mathrm{~h}$, or until the front reached the anodal end of the gel, and then stained for MNR (Conkle et al., 1982).

For each enzyme, the most anodal zone was assigned as 1 , the next 2 , and so on. Allozymes were designated based on their distance from the most common allele at each locus, which was assigned the number 100. 
Table 1. Chi-square analysis for single-gene segregation in guayule progenies.

\begin{tabular}{|c|c|c|c|c|c|}
\hline Enzyme & Crosses & $\begin{array}{c}\text { No. progenies in each } \\
\text { segregating class }\end{array}$ & Test ratio & $x^{2}$ & $P$ value \\
\hline PGM-2 & $\frac{100}{100} \times \frac{100}{117}$ & $25 \frac{100}{100}: 31 \frac{100}{117}$ & $1: 1$ & 0.64 & $0.5-0.1$ \\
\hline PGM-2 & $\frac{100}{100} \times \frac{100}{100}$ & $67 \frac{100}{100}$ & --- & --- & --- \\
\hline PGM-3 & $\frac{100}{100} \times \frac{100}{83}$ & $35 \frac{100}{100}: 39 \frac{100}{83}$ & $1: 1$ & 0.21 & $0.9-0.5$ \\
\hline PGM-3 & $\frac{100}{100} \times \frac{100}{100}$ & $48 \frac{100}{100}$ & --- & -- & --- \\
\hline MNR-1 & $\frac{100}{100} \times \frac{127}{127}$ & $30 \frac{100}{127}$ & --- & -- & --- \\
\hline MNR-2 & $\frac{100}{200} \times \frac{100}{200}$ & $13 \frac{200}{200}: 23 \frac{100}{200}: 20 \frac{100}{100}$ & 1:2:1 & 3.53 & $0.5-0.1$ \\
\hline MNR-2 & $\frac{100}{100} \times \frac{100}{200}$ & $37 \frac{100}{100}: 32 \frac{100}{200}$ & $1: 1$ & 0.36 & $0.9-0.5$ \\
\hline MNR-2 & $\frac{100}{100} \times \frac{100}{100}$ & $56 \frac{100}{100}$ & $\cdots$ & -- & --- \\
\hline
\end{tabular}
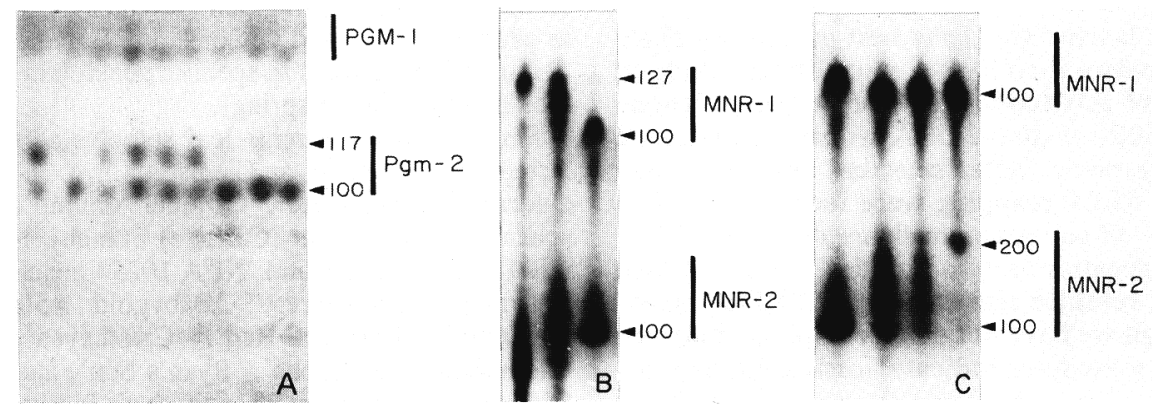

Fig. 2. Expression of PGM and MNR on the starch gels. (A) Segregating progenies at Pgm-2, (left to right), heterozygous parent (117/100), homozygous parent (100/100), and their hybrids (117/100, $117 / 100,117 / 100,117 / 100,100 / 100,100 / 100$, and 100/100). (B) MNR-1 isozyme variant, (left to right) P. tomentosum (127/127), hybrid (127/100), and P. argentatum (100/100). (C) MNR-2 isozyme variant homozygous parents (left) $100 / 100$ and (right) 200/200 and their hybrids (middle) 200/ 100 .

Other alleles were identified as to the percentage of migration distance from the most common allele. Goodness-of-fit to expected segregation ratios was tested using chi-square.

Phosphoglucomutase. The fastest and the slowest migrating zones, PGM-1 and PGM4 , were poorly stained and consequently were not analyzed. PGM-2 and PGM-3 each showed two allozymes (Fig. 1). The slow allozyme of Pgm-2 overlapped the fast allozyme of Pgm-3, giving one diffused band (Figs. 1 and 2A). Heterozygous individuals for Pgm-2 and Pgm-3 loci showed three bands: a fast, a slow, and an intermediate diffused band. The observation of three bands in double heterozygotes may also be due to the presence of a null allele at one of the loci. The former explanation appears more likely because the diffused intermediate band generally stained darker than the other two bands. Occasionally, very light and faint bands were observed on either side of the diffused band, but they were not consistent enough to be scored. Our results indicate that PGM is active as a monomer in guayule, as in other plant species (Gaur and Slinkard, 1990). Inheritance analysis indicated that PGM-2 and PGM-3 are each coded for by a single locus and segregate in the expected $1: 1$ ratio in progeny tests (Table 1 ).

Menadione reductase. MNR showed two zones of activity, MNR-1 and MNR-2. MNR1 was invariant in guayule plants tested. However, a faster-moving band designated as 127 was observed in $P$. tomentosum DC. Interspecific hybrids between guayule and $P$. tomentosum produced a five-banded pattern at the MNR-1 zone (Fig. 2B), which is consistent with the tetrameric structure of this enzyme as demonstrated in Liquidamber L. (Hoey and Parks, 1990), Heliunthus, and Heliomeris (Rieseberg and Soltis, 1989). Parthenium tomentosum and its hybrid with $P$. argentatum showed different banding patterns at MNR-2 (Fig. 2B). However, the resolution of bands was too poor for analyses. In $P$. algentatum, MNR-2 showed two bands representing alleles 100 and 200 (Fig. 2C). MNR-2 is also a tetramer, since it produced five bands in the heterozygote individuals
(Fig. 2C). Inheritance analysis indicated that Mnr-2 is coded for by two alleles at a single locus (Table 1).

Isozyme loci described in the present study extended the number of genetic markers available to identify hybrid progeny of facultative apomictic guayule.

\section{Literature Cited}

Conkle, M.T., P.D. Hodgskiss, L.B. Nunnaly, and S.C. Hunter. 1982. Starch gel electrophoresis of conifer seeds: A laboratory manual. Gen. Tech. Rpt. PSW-64, Pacific Southwest For. and Range Expt. Sta., Berkeley, Calif.

Ellstrand, N.C. 1984. Multiple paternity within the fruits of the wild radish, Raphanus sativus. Amer. Naturalist 123:819-828.

Esau, K. 1944. Apomixes in guayule. Proc. Natl. Acad. Sci. USA 30:352-355.

Garvin, D.F. 1987. The inheritance and linkage of isozyme genes in tepary bean, Phaseolus acutifolius A. Gray. Masters Thesis, Univ. of California, Riverside.

Gaur, P.M. and T.G. Slinkard. 1990. Inheritance and linkage of isozyme coding genes in chickpea. J. Hered. 81:455-461.

Gerstel, D.U. and W. Mishanec. 1950. On the inheritance of apomixis in Parthenium argentatum. Bot. Gas. 112:96-106.

Hashemi, A., A. Estilai, and B. Ehdaie. 1991. Inheritance of aconitase, shikimate dehydrogenase, and phosphoglucose isomerase in guayule (Parthenium argentatum Gray). J. Amer. Soc. Hort. Sci. 116:737-739.

Hashemi, A., J.E. West, and J.G. Waines. 1986. Chromosome pairing and pollen fertility in interspecific hybrids of species of Parthenium (Asteraceae). Amer. J. Bot. 73:980-988.

Heywood, J.S. 1980. Genetic correlations of edaphic differentiation and endemism in Gaillardia. PhD Diss., Univ. of Texas, Austin.

Hoey, M.T. and C.R. Parks. 1990. Isozyme inheritance in the genus Liquidambar L. J. Hered. $81: 455-461$

Rieseberg, L.H. and D.E. Soltis. 1989. Assessing the utility of isozyme number for determining ploidal level: Evidence from Helianthus and Heliomeris (Asteraceae). Aliso 12(2):277-286.

Tysdal, H.M., A. Estilai, LA. Siddiqui, and P.F. Knowles. 1983. Registration of four guayule germplasms. Crop Sci. 23:189. 